\title{
Influence of Trust and Job Satisfaction on Safety Climate among Managers at a Large U.S. Air Carrier
}

\author{
Terrence Kelly ${ }^{1}$, Damon Lercel ${ }^{1, *} \&$ Manoj Patankar ${ }^{1}$ \\ ${ }^{1}$ Center for Aviation Safety Research, Parks College of Engineering, Aviation and Technology, Saint Louis University, \\ St. Louis, Missouri, USA \\ *Corresponding author: Center for Aviation Safety Research, Saint Louis University, St. Louis, Missouri 63103, USA. \\ E-mail: dlercel@slu.edu
}

Received: December 17, 2014

Accepted: January 7, $2015 \quad$ Online Published: April 9, 2015

doi:10.5430/mos.v2n2p57

URL: http://dx.doi.org/10.5430/mos.v2n2p57

\begin{abstract}
Safety climate is a measure of employee attitudes and opinions regarding safety and serves as a snapshot of the overall safety culture within an organization. A review of the safety climate literature suggests that a relationship exists between safety climate and its three component scales: coworker trust, supervisor trust, and job satisfaction. This article examines the influence of trust and job satisfaction on safety climate. A conceptual model was developed based on the literature to test the direct effects of supervisor and coworker trust on job satisfaction, the direct effect of supervisor and coworker trust on safety climate, the direct effect of job satisfaction on safety climate, as well as the indirect effect of supervisor and coworker trust on safety climate mediated by job satisfaction. The overall model was significant with coworker trust and supervisor trust significantly and directly associated with both job satisfaction and safety climate. Additionally the relationship between the two trust scales and safety climate was found to be partially mediated by job satisfaction. These results indicate that safety climate could be improved by implementing programs that focus on coworker trust, supervisor trust, and job satisfaction. The methodology used in this study may provide managers of similar organizations a model to measure the effectiveness and return on investment of actions taken to improve safety climate.
\end{abstract}

Keywords: management; organizational climate; organizational change; aviation safety

\section{Introduction}

It has been over a decade since Mearns and Flin (1999, p. 5) suggested the terms safety culture and safety climate are all too often used "synonymously and interchangeably." The literature has evolved such that a distinction may be drawn between the two and methods are being developed to empirically test aspects of both.

Patankar, Brown, Sabin and Bigda-Peyton (2012) propose an elegant model (See figure 1) for describing organizational safety culture. The model, in the shape of a pyramid, posits a dynamically balanced relationship between the safety values, safety strategies, safety climate and safety behaviors of an organization.

Safety values serve as the foundation of the safety culture pyramid. The underlying values and unquestioned assumptions of the organization serve as the cornerstone by which strategies are developed and put into operation. Strong safety values empower management to set the organizational tone for safety and prescribe organizational priorities.

Safety strategies place into action organizational values surrounding safety. Safety strategies encompass specific safety programs, as well as the management safety structure, individual leadership personnel, policies, procedures and system in place to foster safety.

Safety climate describes the attitudes and opinions about safety and is the result of short and near term influences on the organization and its personnel. Climate reflects the perception of individuals within the organization and is generally considered temporal in nature.

Safety performance represents individual and group behavior and may be reflected in such measures as: employee injury, lost time, aircraft damage, schedule disruption, etc. Safety performance represents the manifestation of those values, strategies, attitudes and opinions held by organizational members surrounding safety. 


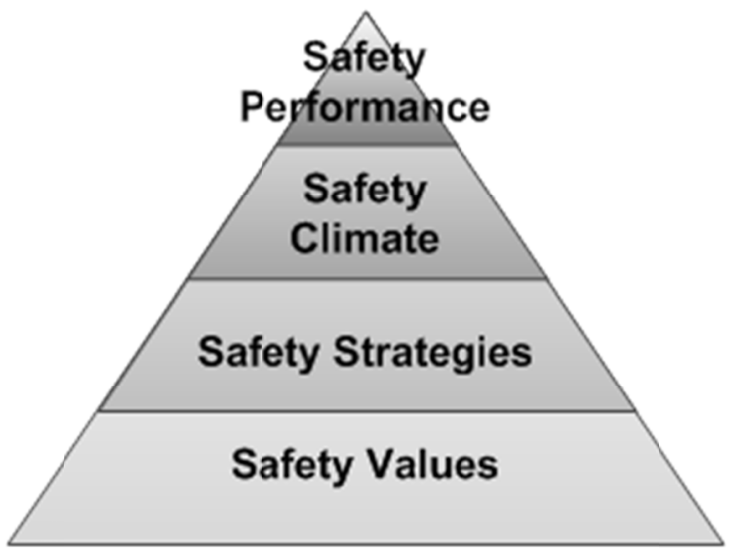

Figure 1. Safety Culture Pyramid

Each level of the Safety Culture Pyramid contributes to the overall safety culture within an organization; consequently, each level should be examined and evaluated to determine its contribution and to identify systemic problems as well as opportunities for improvement. This article focuses on the influence of trust and job satisfaction on safety climate.

\section{Literature Review}

\subsection{Safety Climate}

Patankar, et al. (2012) agree with Mearns, Whitaker and Flin (2001), O'Connor, O’Dea, Kennedy and Buttery (2011) and Guldenmund (2000) in describing safety climate as the attitudes and opinions of organizational members surrounding safety. Harvey, Erdos, Bolam, Cox, Kennedy, and Gregory (2002) support Mearns and Flin (1999) in describing safety climate as reflecting attitudes, perceptions and beliefs. Zohar (1980) suggests a positive safety climate may improve organizational safety. Clarke (2006, p. 324) proposes a link between safety climate and employee safety performance: "Organizational safety climate has an important influence in ensuring adherence to procedures, but, in particular, plays a significant role in the promotion of employee commitment and involvement in safety."

Wiegmann, Zhang, von Thaden, Sharma, and Mitchell, (2002, p. 5) describe safety culture as entrenched and "relatively enduring, stable and resistant to change." In contrast, safety climate is said to be temporal and reflects a snapshot of the safety culture at specific point in time (Denison, 1996; Mearns and Flin, 1999; Wiegmann, 2002). The distinction between safety culture and safety climate is important as the temporal nature of climate represents both risks for safety as well as opportunities for near term safety improvements. In one sense, negative influences may deteriorate safety climate swiftly, resulting in a corresponding decrease in safety performance. Likewise, initiatives aimed at nurturing a positive safety climate may have an immediate effect on safety performance within the organization.

Given the inertia of culture, climate represents a more time sensitive opportunity to influence behaviors within an organization. Clarke (2006, p. 324) asserts "organizational safety climate has an important influence in ensuring adherence to procedures, but, in particular, plays a significant role in the promotion of employee commitment and involvement in safety." Safety climate serves as a "principal guide" in organizational safety performance and provides management with a potent proactive for influencing safety (Gyekye, 2005, p. 291).

Safety climate is said to be influenced by numerous factors. In their study examining the common features of safety climate, Flin, Mearns, O'Connor, and Bryden (2000) include aspects of job satisfaction as contributors to safety climate. In a later study, Flin, Burns, Mearns, Yule, and Robertson (2000) discuss the role of trust in nurturing safety climate. Evidence suggests job satisfaction and trust influence safety climate (Burns, Mearns, and McGeorge, 2006; Cai, 2005; Calvin, 2005; Clarke, 2010; David, Robyn, and Bryan, 2004; Flin et al., 2000; Mearns, Whitaker, and Flin, 2003; Mohamed, 2002). The degree to which job satisfaction and trust independently influence safety climate is unclear. Scholars generally associate trust with job satisfaction (Lau and Liden, 2008; Patankar, 2003; Tan and Lim, 2009), but little is understood regarding the mediating role of job satisfaction when predicting the influence of trust on safety climate. 


\subsection{Job Satisfaction}

Job satisfaction has been regarded as attitudinal in nature and the sum of both positive and negative perceptions of the workplace. Hoppock's (1935) seminal work suggests a premise that defines employee job satisfaction in terms of psychological, physiological and environmental attributes. An individual satisfied in their work is thought to be content in their work life. Likewise, job satisfaction presupposes the individual is physically capable of performing work tasks without undue distress and fatigue. Job satisfaction is contingent on an environment that allows the psychological and physiological attributes to emerge. An employee may demonstrate dissatisfaction if the sum of psychological, physiological or environmental attributes falls below a perceived tolerance level. Likewise, any individual attribute dropping below a given threshold has the potential to negatively affect job satisfaction.

The majority of job satisfaction studies are conducted on line employees, whose job satisfaction is based on physical and mental well-being, and it has been demonstrated to influence their productivity, organizational citizenship and communication.(Grant, 2008; Petrescu, and Simmons, 2008; Proudfoot, Corr, Guest, and Dunn, 2009). Fewer studies assess job satisfaction among managers and no studies have been identified that assess the effect of management's job satisfaction on safety climate.

\subsection{Interpersonal Trust}

Interpersonal trust has been described as a "social lubricant" (Berg, Dickhaut, and McCabe, 1995; Mayer, Davis, and Schoorman, 1995; McAllister, 1995; Reason, 1990), facilitating collective efforts and perceptions within the organization. Burns, Mearns and McGeorge (2006, p. 1140) quote Rousseau, Sitkin, Burt, and Camerer (1998) who state "although the concept of trust appears in a variety of senses in the social sciences, it is now widely regarded as a psychological state comprising the intention to accept vulnerability based upon positive expectations of the intentions or behavior of another."

The literature is inconsistent regarding the notion of trust as a single construct. Conchie and Donald (2006, p. 1151) describe trust from two perspectives: (a) a risk-theorist perspective that describes trust in terms of trust versus distrust and (b) a safety professional perspective that describes trust along a continuum from low to high. This report uses the safety professional perspective on interpersonal trust.

Taylor and Thomas (2003, p. 3) identify trust as a "key to building aviation organizations with excellent safety records." Jeffcott, Pidgeon, Weyman and Walls (2006) suggest trust influences the attitudes and opinions of organizational citizens as well as the systems in which they exist. As trust influences attitudes and opinions surrounding safety, trust becomes a component within an organization's safety climate.

Research (Conchie and Donald, 2006; Cox, Jones, and Collinson, 2006) suggests that trust remains largely under-researched within the context of high-reliability organizations. Numerous articles have been authored which examine and discuss the role of trust between employees and trust between employees and management (Barling, Kelloway, and Iverson, 2003; Mearns et al., 2001; Mohamed, 2002; Patankar, 2003; Taylor and Thomas, 2003). The literature appears absent of research examining trust shared by managers in each other and how managerial coworker trust affects job satisfaction and the safety climate of an organization.

\subsection{Supervisor Trust and Job Satisfaction}

Tan and Tan (2000) identify ability, benevolence, and integrity as antecedents for developing trust in a supervisor. The perception of a supervisor's professional abilities will influence the subordinates' trust in that supervisor. Supervisors who lack the skillset to perform subordinate tasks lack professional credibility. When subordinates believe a supervisor is skilled and proficient in work tasks, they believe the supervisor will be better able to assist when problems arise. A supervisor who is seen as benevolent, characterized by good faith behavior and kindness, will engender trust in subordinates. Tan and Tan (p. 244) maintain that a "supervisor is considered to have integrity if he or she is perceived to be consistent and credible, with a strong sense of justice regarding actions that are congruent with words." The supervisor without ability, benevolence, and integrity is likely to be perceived as untrustworthy.

The role of supervisor trust in a subordinate's job satisfaction has been a matter of multiple empirical studies (Burke, Sims, Lazzara, and Salas, 2007; Dirks and Ferrin, 2002; Driscoll, 1978). Dirks and Ferrin's (2002) meta-analysis of supervisor trust linked trust in supervisor to job satisfaction while Driscoll's (1978) research suggests supervisor trust was a useful predictor of job satisfaction. Taylor and Thomas (2003, p. 4) cite Mishra (1996) in stating "trust facilitates truthful communication and leads to collaboration," both of these attributes are necessary for job satisfaction. In addition to fostering open communication and collaboration, trust in supervisor tends to foster an environment in which individuals maintain a sense of security and mutual respect. Individuals who trust their 
supervisor believe they will be heard and have influence over organizational decision-making. Given arguments made in the literature, supervisor trust should positively predict job satisfaction.

\subsection{Supervisor Trust and Safety Climate}

The role of supervisor trust and its effect on safety climate has been documented in a number of research articles. Flin et al. (2000) and Mearns et al. (2001) discuss the multitude of dimensions examined by researchers for measuring safety climate, including the role of supervisor trust. Zohar and Luria's (2005, p. 625) comments reflect the need for trust throughout the management hierarchy in prioritizing safety: "Supervisors whose immediate superiors put greater emphasis on safety will execute formal safety procedures more diligently than those whose superiors are less interested in such issues, although they continue to exercise discretionary power."

Mearns et al. (2001, p. 779) benchmarked safety climate in hazardous environments utilizing research questions surrounding supervisor trust and competence. Their study suggests that when subordinates opinions regarding management's commitment to safety improve, the safety climate also improves: "Perceived management commitment was highly positively correlated with satisfaction with safety activities, willingness to report incidents, and perceived supervisor competence." Given these arguments made in the literature, supervisor trust should positively predict safety climate.

\subsection{Coworker Trust and Job Satisfaction}

Coworker trust embodies many of the same characteristics of management trust with the exception that "unlike relationships between individuals in authority (i.e., supervisors) and organizations, relationships between coworkers are characterized by little or no power imbalance" (Tan and Lim, 2009, p. 46)." Tan and Lim specify coworker trust as the "willingness of a person to be vulnerable to the actions of fellow coworkers whose behavior and actions that person cannot control."

Lau and Liden (2008) argue the interdependent nature of most work tasks requires coworkers to trust and collaborate with each other to achieve organizational goals. This collaboration fosters trust building as individuals contribute collectively to the organization and are generally compensated or penalized as a collective unit. Coworker trust becomes a necessary attribute for organization success.

Social Exchange Theory posits that individuals operate in social environments and a rational system of give-and-take occurs in order to achieve desired outcomes (Homans, 1958). The system is balanced by a series of negotiated or reciprocal exchanges between individuals (Molm, Takahashi, and Peterson, 2000). Social exchange is based on trust between individuals to either fulfill a negotiated obligation or reciprocate with an exchange of similar value. Konovsky and Pugh (1994, p. 658) argue that "trust is a key element in the emergence and maintenance of social exchange relationships." When interdependence among coworkers is essential to job success, trust generally emerges between coworkers as a necessity. Coworker trust is integral to developing an environment that is able to sustain high levels of job satisfaction (Aryee, Budhwar, and Chen, 2002; Ferres, Connell and Travaglione, 2004). Consequently, coworker trust should positively predict job satisfaction.

\subsection{Coworker Trust and Safety Climate}

Ferres et al. (2004) provide empirical support suggesting coworker trust is essential in fostering positive workplace attitudes and perceptions. In the context of safety, Conchie et al. (2006, p. 1097) describe trust as "an individual's willingness to rely on another person based on expectations that he or she will act safely or intends to act safely." An organization replete with members who trust each other will find building a strong safety climate less burdensome. Based on climate defined as the attitudes and opinions of employees, trust in coworkers will likely foster communication and lead to a workplace environment of sincerity, security and conviction surrounding safety. Coworker trust should positively predict safety climate.

As an attitudinal aspect of an individual's work life, job satisfaction contributes to the overall safety climate of an organization. (Flin et al., 2000; Gillen, Baltz, Gassel, Kirsch, and Vaccaro, 2002; Pronovost and Sexton, 2005). This is consistent with Clarke (2010) who observed safety climate is mediated by job satisfaction. Lee (1998) identified a high level of job satisfaction as a characteristic of low accident work environments.

Evolving research in safety climate supports the premise that job satisfaction is related to safety climate. Clarke (2010) argues that individuals who are satisfied in their jobs will be more likely to follow safety related rules and policies and make an extra effort to participate in safety related activities. Clarke (2010, p. 558), further states "A positive safety climate, in which employees perceive that safety is prioritized and that managers are committed to safety, is likely to increase employees' feelings of commitment and satisfaction with the organization." 
The literature is less clear regarding the mediating effects of job satisfaction on safety climate. Researchers suggest a relationship between trust and job satisfaction (Burke et al., 2007; Dirks and Ferrin, 2002; Driscoll, 1978) and trust and safety climate (Flin, Burns, Mearns, Yule, and Robertson, 2006; Mearns et al., 2001). Additionally, a relationship between job satisfaction and safety climate is thought to exist (Flin et al., 2000; Gillen et al., 2002; Pronovost and Sexton, 2005). What remains unexplained is whether the relationship between job satisfaction and safety climate is unique or if the role of trust within job satisfaction explains the relationship. Job satisfaction should positively predict safety climate. Job satisfaction may mediate the prediction of safety climate based on trust.

\section{Methodology}

A conceptual model was developed, based on the literature, to better understand the strength of relationship between coworker trust, supervisor trust and job satisfaction on safety climate. The model was designed to test the direct effects of supervisor and coworker trust on job satisfaction, the direct effect of supervisor and coworker trust on safety climate, and the direct effect of job satisfaction on safety climate, as well as the indirect effect of supervisor and coworker trust on safety climate. See Figure 2 for the illustration of supervisor trust, coworker trust, and job satisfaction as factors influencing safety climate.

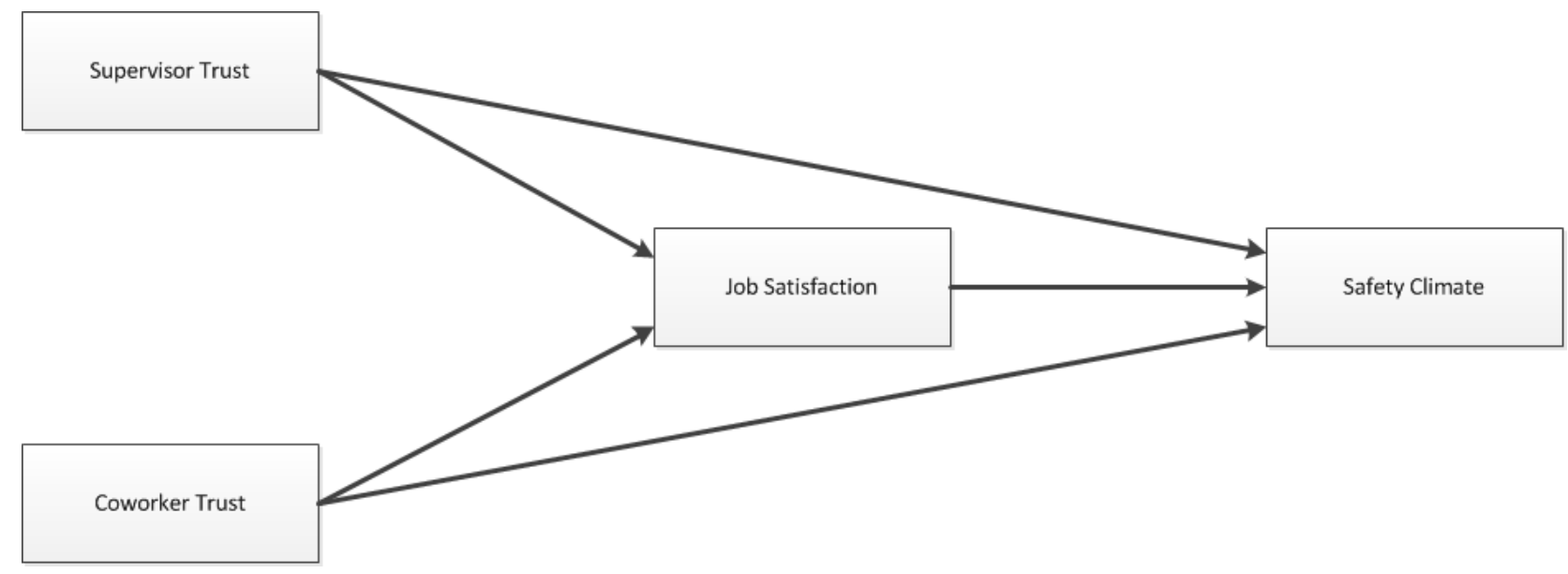

Figure 2. Theoretical Path Model

Data were collected from management personnel using a 100-item survey instrument, which included items intended to measure supervisor and coworker trust, job satisfaction, and safety climate.

The survey instrument itself is a composite, consisting of questions selected from the Cockpit Management Attitudes Questionnaire developed by Helmreich (1984), the Maintenance Resource Management/Technical Operations Questionnaire (Taylor, 2000), the Command Safety Assessment Questionnaire (Ciavarelli and Figlock, 1996) and the Organizational Safety Culture Questionnaire (Patankar, 2003). Additional questions were added to the instrument by the research team to verify elements of Patankar et al. (2012) Safety Culture Pyramid Model.

According to Helmreich and Merritt (1998), the Cockpit Management Attitudes Questionnaire provides an objective index of cockpit-management attitudes in an effort to provide a snapshot of an organization. The Maintenance Resource Management/ Technical Operations Questionnaire developed by Taylor (2000, p. 217) was "developed to measure the attitudes and intentions of participants in airline maintenance communication and safety training workshops." The Aviation Command Safety Assessment survey was designed to measure the extent to which a particular naval squadron met criteria of a so-called High Reliability Organization (Ciavarelli and Figlock, 1996). The Organizational Safety Culture Questionnaire (Patankar, 2003) was designed to measure safety climate across a broad set of aviation personnel including pilots, mechanics and management.

See Table 1 for example questions associated with each scale. The Supervisor trust scale utilized direct and indirect items intended to capture the respondent's level of trust in their supervisor. Likewise, coworker trust was measured using items intended to measure interpersonal trust levels by providing unique scenarios of coworker interaction and then extracting trust perceptions. Job satisfaction was measured with a cross-section of items designed to address many of the characteristics found in the literature and associated with an individual's level of job satisfaction. The diversity and temporal nature of safety climate relied on items intended to be short or near term manifestations of 
attitudes and opinions surrounding safety. Some items in the survey instrument were negatively coded to strengthen the overall validity of the measures.

Table 1. Example Questions from Emergent Scales

\begin{tabular}{llll}
\hline \multicolumn{1}{c}{ Supervisor Trust } & \multicolumn{1}{c}{ Coworker Trust } & Job Satisfaction & \multicolumn{1}{c}{ Safety Climate } \\
\hline $\begin{array}{l}\text { My supervisor can be } \\
\text { trusted }\end{array}$ & $\begin{array}{l}\text { If I had problems at work, } \\
\text { I know my coworkers } \\
\text { would try to help me out } \\
\text { Mhen I make an }\end{array}$ & $\begin{array}{l}\text { The work I do is very } \\
\text { meaningful to me. }\end{array}$ & $\begin{array}{l}\text { This organization does not } \\
\text { compromise safety to get } \\
\text { the job done }\end{array}$ \\
$\begin{array}{l}\text { Most my coworkers } \\
\text { will support me }\end{array}$ & $\begin{array}{l}\text { The work gives me a } \\
\text { sense of achievement }\end{array}$ & $\begin{array}{l}\text { I regard this organization } \\
\text { and its work as safe }\end{array}$ \\
$\begin{array}{l}\text { My concerns about they say they will do } \\
\text { safety would be acted } \\
\text { on if I expressed them } \\
\text { to my supervisor }\end{array}$ & $\begin{array}{l}\text { I cannot rely on my } \\
\text { coworkers to do high } \\
\text { quality work. (reverse } \\
\text { coded) }\end{array}$ & $\begin{array}{l}\text { Most days I am } \\
\text { enthusiastic about my } \\
\text { work }\end{array}$ & $\begin{array}{l}\text { Safety is a core value in } \\
\text { this organization }\end{array}$ \\
\hline
\end{tabular}

The survey instrument was provided to management personnel at the partner air carrier and respondents were asked to rate their level of agreement with survey instrument statements. Responses were recorded on a 5-point Likert-type scale. The range of the scale was as follows: $1=$ Strongly Disagree., $2=$ Slightly Disagree., $3=$ Neutral., $4=$ Slightly Agree., 5 = Strongly Agree.

Survey instruments were forwarded to all $1299(\mathrm{~N}=1299)$ management employees falling under Operations (flight, engineering, maintenance, quality, etc.), thus those employees involved in other aspects of the airline were not included. A sample size estimate was based on a confidence level of $95 \%$ and a confidence interval of 5\% including a correction for finite populations. The researchers determined a sample size of approximately 300 cases would be adequate based on calculations and confirmation in the literature (Krejcie, and Morgan, 1970).

A total of $729(n=729)$ useable survey instruments were returned for a response rate of $57.7 \%$. The tenure for respondents was approximately 15 years and $75 \%$ of them were male and $25 \%$ of them were female.

A Principles Components Analysis with Varimax rotation was accomplished in order to reduce the survey questions into coherent constructs. A Bartlett's Test of Sphericity was significant $(\rho<0.001)$ and a Kaiser Meyer Olkin $(0.958)$ test indicated appropriateness for the analysis. Specifying Eigen values of no less than one resulted in nine distinct scales. Consistent with previous research, supervisor trust, coworker trust, job satisfaction, and safety climate scales emerged from the data. Ordinal level data contributing to each scale were summed and a new ratio variable for each scale was created. Path analysis was conducted on the new ratio variables.

A regression based path analysis was performed to determine the direct influence of supervisor trust on job satisfaction, coworker trust on job satisfaction and job satisfaction on safety climate. Additionally, job satisfaction was regressed against supervisor and coworker trust in predicting safety climate in order to determine the mediating effects of job satisfaction on safety climate.

\section{Results}

The overall model was statistically significant, $\mathrm{F}(3,748)=176.35, \mathrm{p}<.001$, and accounted for approximately $42 \%$ of the variance in safety climate $(\mathrm{R} 2=.415$, Adjusted $\mathrm{R} 2=.413)$. A Pearson correlation coefficient was calculated for each pair of scales. Results indicate a moderately high correlation between supervisor trust, coworker trust, job satisfaction and safety climate. Table 2 provides correlation, significance, mean and standard deviation values for the variables included in the model. It should be noted that high correlations suggest an association but do not represent causality. Supervisor and coworker trust were the most highly correlated $(r=0.609, \rho<0.01)$ while job satisfaction and safety climate shared the next highest correlation $(r=0.559, \rho<0.01)$. The lowest correlation between the scales examined was $r=0.492(\rho<0.01)$ between coworker trust and safety climate. 
Table 2. Means, Standard Deviations (SD), and Correlations for Variables $(\mathrm{n}=729)$

\begin{tabular}{lllllll}
\hline & \multicolumn{1}{c}{ Correlations } \\
\hline Variable Name & 1 & 2 & 3 & 4 & Mean & $S D$ \\
\hline 1. Supervisor Trust & 1 & $0.609 * *$ & $0.535^{* *}$ & $0.550^{* *}$ & 38.22 & 6.89 \\
2. Coworker Trust & $0.609 * *$ & 1 & $0.502 * *$ & $0.492 * *$ & 24.18 & 4.42 \\
3. Job Satisfaction & $0.535^{* *}$ & $0.502 * *$ & 1 & $0.559 * *$ & 37.67 & 6.23 \\
4. Safety Climate & $0.550 * *$ & $0.492 * *$ & $0.559 * *$ & 1 & 97.95 & 17.49 \\
$* *$ Correlation is significant at the 0.01 level (2-tailed) & & & \\
\hline
\end{tabular}

Figure 3 illustrates the results of the path analysis including standardized path coefficients $(\beta)$ in the form of standardized regression weights, path coefficient significance $(\rho)$, Pearson correlation coefficients in parenthesis and error variance $(\varepsilon)$.

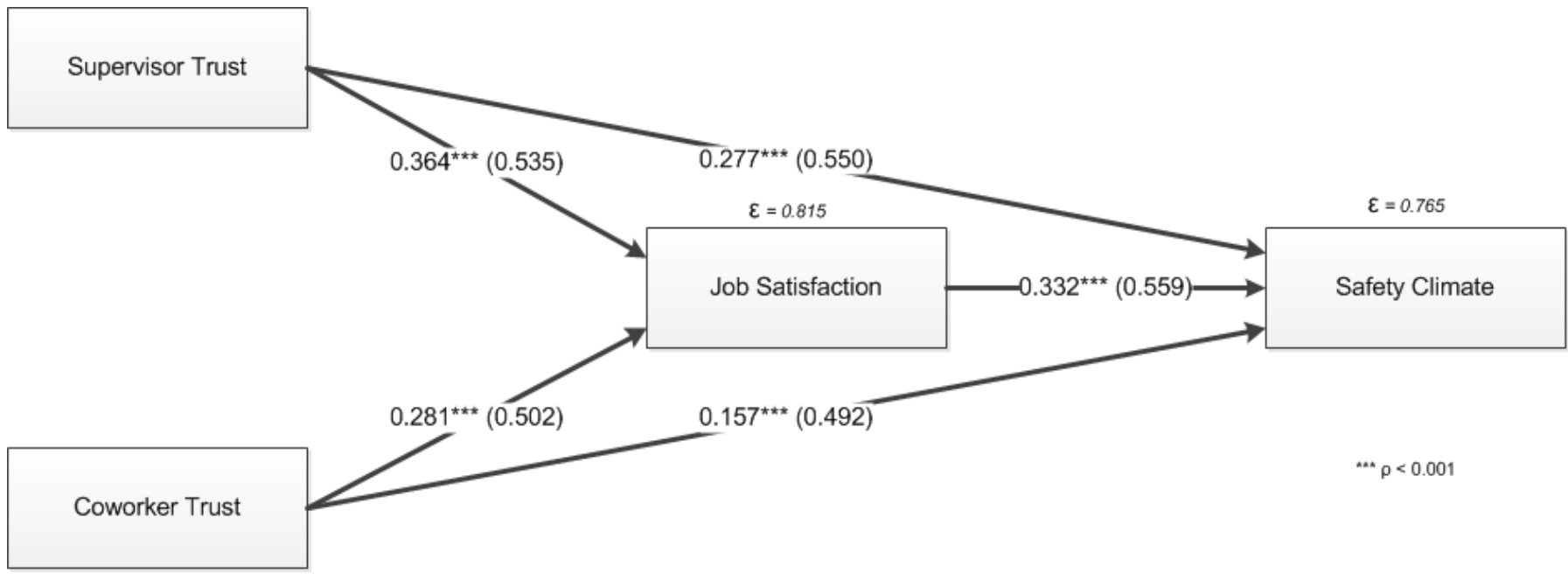

Figure 3. Path Model Results

Results of the path analyses indicate supervisor trust had a significant positive direct effect on both job satisfaction $(\beta$ $=0.364)$ and safety climate $(\beta=0.277)$. Coworker trust was determined to have a significant positive direct effect on job satisfaction $(\beta=0.281)$ and safety climate $(\beta=0.157)$. Job satisfaction $(\beta=0.332)$ was found to have a significant direct effect on safety climate.

Table 3 includes standardized coefficients, unstandardized coefficients, standard error, t-value and error variance $(\varepsilon)$. Supervisor trust and coworker trust accounted for $34 \%$ of the variance in job satisfaction while supervisor trust, coworker trust and job satisfaction accounted for $42 \%$ of the variance in safety climate. The unexplained variance in the model predicting job satisfaction was $82 \%$ while the unexplained variance in predicting safety climate was $77 \%$.

Table 3. Decomposition of Effects from Path Analysis

\begin{tabular}{|c|c|c|c|c|c|c|}
\hline Effect & $\begin{array}{l}\text { Unstandardized } \\
\text { Coefficient }\end{array}$ & $\begin{array}{l}\text { Standard } \\
\text { Error }\end{array}$ & $\begin{array}{l}\text { Standardized } \\
\text { Coefficient }\end{array}$ & $t$ & $\varepsilon$ & $R^{2}$ \\
\hline Supervisor Trust on Job Sat. & 0.328 & 0.034 & 0.364 & $9.661 * *$ & 0.815 & 0.335 \\
\hline Coworker Trust on Job Sat. & 0.396 & 0.053 & 0.281 & $7.466 * *$ & & \\
\hline $\begin{array}{l}\text { Supervisor Trust on Safety } \\
\text { Climate }\end{array}$ & 0.703 & 0.095 & 0.277 & $7.401 * *$ & 0.765 & 0.415 \\
\hline $\begin{array}{l}\text { Coworker Trust on Safety } \\
\text { Climate }\end{array}$ & 0.621 & 0.145 & 0.157 & $4.283 * *$ & & \\
\hline $\begin{array}{l}\text { Job Sat. On Safety Climate } \\
* * \rho<0.001\end{array}$ & 0.932 & 0.096 & 0.331 & $9.656 * *$ & & \\
\hline
\end{tabular}




\section{Discussion}

A model was developed to predict the effect of an air carrier management perception of supervisor and coworker trust on job satisfaction and supervisor and coworker trust and job satisfaction on safety climate. The model tested the mediating effects of job satisfaction on supervisor and coworker trust when predicting safety climate.

Consistent with the literature, supervisor trust significantly predicted job satisfaction $(\beta=0.364)$. This is consistent with the studies by Driscoll (1978), Dirks and Ferrin (2002), and Burke et al. (2007). Trust between a subordinate and their supervisor is thought to improve communication and collaboration, thus improving the overall level of job satisfaction. Trust in a supervisor appears to engender a sense of job security in the subordinate and is said in the literature to support an environment of inclusion, which fosters participation. The symbol $\beta$ represents a standardized coefficient; consequently, a single unit increase in supervisor trust will increase job satisfaction by 0.364 units.

Coworker trust significantly predicts job satisfaction $(\beta=0.281)$. This measurement is consistent with Lau and Liden's (2008) premise suggesting the interdependence of work tasks. In order to realize the rewards associated with organizational success, coworkers must rely on each other and work collectively to achieve organizational goals. Consequently, when coworker trust is high, the organization is better positioned to meet its goals and improve job satisfaction among its employees. A one-unit increase in coworker trust will increase job satisfaction by 0.281 units.

Supervisor trust was a significant predictor of safety climate $(\beta=0.277)$. This result is consistent with Flin (2000) and Mearns et al. (2001) observations regarding the effect of supervisor trust on safety climate. Zohar (2002) argues supervisor credibility is based on the idea of competence. The results suggest supervisor trust at the partner air carrier likely prioritizes safety and follows through with resources that support a safe working environment. A one-unit increase in supervisor trust will increase safety climate by 0.277 units.

Coworker trust also significantly predicts safety climate $(\beta=0.157)$. Safety climate has been defined as the attitudes and opinions surrounding the overall safety within an organization. Taylor and Thomas (2003), Patankar (2003) and O'Connor et al. (2011) all suggest that higher levels of coworker trust will improve the attitudes and opinions surrounding safety. Without a high degree of coworker trust, confidence in the attention to safety priorities will suffer and the overall safety climate will be negatively affected. A one-unit increase in coworker trust will increase safety climate by 0.157 units.

The indirect effect of supervisor trust on safety climate through job satisfaction $\beta=0.121(0.364 * 0.332)$ was less than half of the direct effect of $\beta=0.277$. The indirect effect of coworker trust on safety climate was also mediated by job satisfaction $\beta=0.093(0.281 * 0.332)$ compared to the direct effect of $\beta=0.157$. As figure 3 illustrates, the standardized coefficient between supervisor trust and safety climate and coworker trust and safety climate both decreased considerably when controlling for job satisfaction. The results suggest that safety climate will deteriorate when supervisor trust suffers, even if employees perceive positive job satisfaction. To a somewhat lesser extent, safety climate will decrease, in spite of good job satisfaction, when coworker trust is lost. Supervisor trust was the strongest predictor of safety climate amongst the factors considered.

Supervisor and coworker trust accounted for the $34 \%$ of the systematic variance in job satisfaction and $42 \%$ of the systematic variance in safety climate. These values represent substantial contributions to both job satisfaction and safety climate. The unexplained variance (non-systematic) of $82 \%$ for job satisfaction and $77 \%$ for safety climate suggest that the model does not represent the majority of scales contributing to both job satisfaction and safety climate. Organizations may see significant improvements in safety culture (attitudes and opinions) by prioritizing supervisor and coworker trust and addressing issues that lead to poor job satisfaction.

\section{Limitations}

It should be noted the data used in this report represent the managers in the partner air carrier and did not include labor. Consequently, the results should not be generalized to the entire organization or to other air carriers or other types of organizations.

The model only suggests a partial causality for the entirety of job satisfaction and safety climate. Additional variables, identified in the literature and supported by empirical testing will provide the framework for constructing a more robust model.

\section{Acknowledgements}

The authors thank Yvonne Cuaycong for providing administrative support and the Federal Aviation Administration 
for providing funding for this research.

\section{References}

Aryee, S., Budhwar, P.S., \& Chen, Z.X. (2002). Trust as a mediator of relationships between organizational justice and work outcomes: test of a social exchange model. Journal of Organizational Behavior, 23, 267-285.

Barling, J., Kelloway, K., \& Iverson, R. (2003). High-quality work, job satisfaction, and occupational injuries. Journal of Applied Psychology, 88(2), 276-283. http://dx.doi.org/10.1037/0021-9010.88.2.276

Berg, J., Dickhaut, J., \& McCabe, K. (1995). Trust, Reciprocity, and Social History. Games and Economic Behavior, 10(1), 122-142. http://dx.doi.org/ 10.1006/game.1995.1027

Burke, C. S., Sims, D. E., Lazzara, E. H., \& Salas, E. (2007). Trust in leadership: A multi-level review and integration. The Leadership Quarterly, 18(6), 606-632. http://dx.doi.org/10.1016/j.leaqua.2007.09.006

Burns, C., Mearns, K., \& McGeorge, P. (2006). Explicit and Implicit Trust Within Safety Culture. Risk Analysis: An International Journal, 26(5), 1139-1150.

Cai, W. (2005). The impact of safety culture on safety performance: A case study of a construction company. Ph.D. 3199404, Indiana University, United States--Indiana. Retrieved from http://proquest.umi.com/pqdweb?did=1031042621 andFmt=7andclientId=26447andRQT=309andVName=PQD

Calvin, B. (2005). Dual Attitudes about Trust in Safety Culture. The Business Review, Cambridge, 4(2), 92.

Ciavarelli, A., \& Figlock, R. (1996). Organizational factors in aviation accidents. Paper presented at the Ninth Annual Symposium on Aviation Psychology, Columbus, $\mathrm{OH}$.

Clarke, S. (2006). The relationship between safety climate and safety performance: A meta-analytic review. Journal of Occupational Health Psychology, 11(4), 315-327. http://dx.doi.org/10.1037/1076-8998.11.4.315

Clarke, S. (2010). An integrative model of safety climate: Linking psychological climate and work attitudes to individual safety outcomes using meta-analysis. Journal of Occupational and Organizational Psychology, 83(3), 553-578. http://dx.doi.org/10.1348/096317909x452122

Conchie, S. M., \& Donald, I. J. (2006). The Role of Distrust in Offshore Safety Performance. Risk Analysis: An International Journal, 26(5), 1151-1159.

Cox, S., Jones, B., \& Collinson, D. (2006). Trust Relations in High-Reliability Organizations. Risk Analysis: An International Journal, 26(5), 1123-1138.

David, M. D., Robyn, R. M. G., \& Bryan, S. S. (2004). Safety Climate: Assessing management and organizational influences on safety. Professional Safety, 49(7), 50.

Denison, D. R. (1996). What is the difference between organizational culture and organizational climate? A native's point of view on a decade of paradigm wars. Academy of Management Review, 21(3), 619-654. http://dx.doi.org/10.5465/amr.1996.9702100310

Dirks, K. T., \& Ferrin, D. L. (2002). Trust in leadership: Meta-analytic findings and implications for research and practice. Journal of Applied Psychology, 87(4), 611-628. http://dx.doi.org/10.1037/0021-9010.87.4.611

Driscoll, J. W. (1978). Trust and Participation in Organizational Decision Making as Predictors of Satisfaction. The Academy of Management Journal, 21(1), 44-56.

Ferres, N., Connell, J., \& Travaglione, A. (2004). Co-worker trust as a social catalyst for constructive employee attitudes. Journal of Management Psychology, 19, 608-622.

Flin, R., Burns, C., Mearns, K., Yule, S. J., \& Robertson, E. (2006). Measuring safety climate in health care. Quality and Safety in Health Care, 15, 109-115.

Flin, R., Mearns, K., O'Connor, P., \& Bryden, R. (2000). Measuring safety climate: identifying the common features. Safety Science, 34(1-3), 177-192. http://dx.doi.org/10.1016/s0925-7535(00)00012-6

Gillen, M., Baltz, D., Gassel, M., Kirsch, L., \& Vaccaro, D. (2002). Perceived safety climate, job demands, and coworker support among union and nonunion injured construction workers. Journal of Safety Research, 33(1), 33-51. http://dx.doi.org/10.1016/s0022-4375(02)00002-6

Grant, A. M. (2008). Does intrinsic motivation fuel the prosocial fire? Motivational synergy in predicting persistence, 
performance, and productivity. Journal of Applied Psychology, 93(1), 48-58. http://dx.doi.org/10.1037/0021-9010.93.1.48

Guldenmund, F. W. (2000). The nature of safety culture: a review of theory and research. Safety Science, 34(1-3), 215-257. http://dx.doi.org/10.1016/s0925-7535(00)00014-x

Gyekye, S., A. (2005). Workers' perceptions of workplace safety and job satisfaction. International Journal of Occupational and Safety Ergonomics, 11(3), 291-302.

Harvey, J., Erdos, G., Bolam, H., Cox, M. A. A., Kennedy, J. N. P., \& Gregory, D. T. (2002). An analysis of safety culture attitudes in a highly regulated environment. Work and Stress, 16(1), 18-36.

Helmreich, R. (1984). Cockpit Management Attitudes. Human Factors, 26(5), 583-589.

Helmreich, R., \& Merritt, A. (1998). Culture at work in aviation and medicine: National, organizational and professional Influences. Aldershot, U.K.: Ashgate Publishing Ltd.

Homans, G. C. (1958). Social Behavior as Exchange. American Journal of Sociology, 63(6), 597-606.

Hoppock, R. (1935). Job Satisfaction. New York: Harper Brothers.

Jeffcott, S., Pidgeon, N., Weyman, A., \& Walls, J. (2006). Risk, Trust, and Safety Culture in U.K. Train Operating Companies. Risk Analysis: An International Journal, 26(5), 1105-1121.

Konovsky, M. A., \& Pugh, S. D. (1994). Citizenship behavior and social exchange. Academy of Management Journal, 37(3), 656.

Krejcie, R.V., \& Morgan, D.V. (1970). Determining sample size for research activities. Educational and Psychological Measurements, 30, 607-610.

Lau, D. C., \& Liden, R. C. (2008). Antecedents of coworker trust: Leaders' blessings. Journal of Applied Psychology, 93(5), 1130-1138. http://dx.doi.org/10.1037/0021-9010.93.5.1130

Lee, T. (1998). Assessment of safety culture at a nuclear reprocessing plant. Work and Stress, 12(3), 217-237. http://dx.doi.org/10.1080/02678379808256863

Mayer, R. C., Davis, J. H., \& Schoorman, F. D. (1995). An integrative model of organizational trust. Academy of Management Review, 20(3), 709-734. http://dx.doi.org/10.5465/amr.1995.9508080335

McAllister, D. J. (1995). Affect and cognition-based trust as foundations for interpersonal cooperation in organizations. Academy of Management Journal, 38(1), 24-59. http://dx.doi.org/10.2307/256727

Mearns, K., \& Flin, R. (1999). Assessing the state of organizational safety-culture or climate? Current Psychology, 18(1), 5-17. http://dx.doi.org/10.1007/s12144-999-1013-3

Mearns, K., Whitaker, S. M., \& Flin, R. (2001). Benchmarking Safety Climate in Hazardous Environments: A Longitudinal, Interorganizational Approach. Risk Analysis: An International Journal, 21(4), 771-786.

Mearns, K., Whitaker, S. M., \& Flin, R. (2003). Safety climate, safety management practice and safety performance in offshore environments. Safety Science, 41(8), 641-680. http://dx.doi.org/10.1016/s0925-7535(02)00011-5

Mishra, A. K. (1996). Organizational responses to crisis: The centrality of trust. In R. M. T. Kramer, T.R (Ed.), Trust in organizations. Thousand Oaks: Sage Publications.

Mohamed, S. (2002). Safety Climate in Construction Site Environments. Journal of Construction Engineering and Management, 128(5), 375.

Molm, L. D., Takahashi, N., \& Peterson, G. (2000). Risk and Trust in Social Exchange: An Experimental Test of a Classical Proposition. American Journal of Sociology, 105(5), 1396-1427.

O'Connor, P., O'Dea, A., Kennedy, Q., \& Buttrey, S. E. (2011). Measuring safety climate in aviation: A review and recommendations for the future. Safety Science, 49(2), 128-138. http://dx.doi.org/10.1016/j.ssci.2010.10.001

Patankar, M., Brown, J., Sabin, E., \& Bigda-Peyton, T. (2012). Safety Culture: Building and Sustaining a Cultural Change in Aviation and Health Care. Aldershot, U.K.: Ashgate Publishing Limited.

Patankar. (2003). A study of safety culture at an aviation organization. International journal of applied aviation studies, 3(2), 243-258.

Petrescu, A., \& Simmons, R. (2008). Human Resource Management Practices and Workers' Job Satisfaction. International Journal of Manpower, 29(7), 651-667. 
Pronovost, P., \& Sexton, B. (2005). Assessing safety culture: guidelines and recommendations. Quality and Safety in Health Care, 14(4), 231-233. http://dx.doi.org/10.1136/qshc.2005.015180

Proudfoot, J. G., Corr, P. J., Guest, D. E., \& Dunn, G. (2009). Cognitive-behavioural training to change attributional style improves employee well-being, job satisfaction, productivity, and turnover. Personality and Individual Differences, 46(2), 147-153. http://dx.doi.org/10.1016/j.paid.2008.09.018

Reason, J. T. (1990). Human Error. New York: Cambridge University Press.

Rousseau, D. M., Sitkin, S. B., Burt, R. S., \& Camerer, C. (1998). Not so different after all: A cross-discipline view of trust. Academy of Management Review, 23(3), 393-404. http://dx.doi.org/10.5465/amr.1998.926617

Tan, H. H., \& Lim, A. K. H. (2009). Trust in Coworkers and Trust in Organizations. Journal of Psychology, 143(1), 45-66.

Tan, H. H., \& Tan, C. S. F. (2000). Toward the differentiation of trust in supervisor and trust in organization. Genetic, Social, and General Psychology Monographs, 126(2), 241-260.

Taylor, J. C. (2000). Reliability and validity of the Maintenance Resources Management/Technical Operations Questionnaire. International Journal of Industrial Ergonomics, 26(2), 217-230. http://dx.doi.org/10.1016/s0169-8141(99)00067-0

Taylor, J. C., \& Thomas, R. L. (2003). Toward Measuring Safety Culture in Aviation Maintenance: The Structure of Trust and Professionalism. International Journal of Aviation Psychology, 13(4), 321.

Wiegmann, D., Zhang, H., von Thaden, T., Sharma, G., \& Mitchell, A. (2002). A synthesis of safety culture and safety climate research(Tech. Rep.). Aviation Research Lab, Institute of Aviation, University of Illinois at Urbana-Champaign.

Zohar, D. (1980). Safety climate in industrial organizations: Theoretical and applied implications. Journal of Applied Psychology, 65(1), 96-102. http://dx.doi.org/10.1037/0021-9010.65.1.96

Zohar, D. (2002). The Effects of Leadership Dimensions, Safety Climate, and Assigned Priorities on Minor Injuries in Work Groups. Journal of Organizational Behavior, 23(1), 75-92.

Zohar, D., \& Luria, G. (2005). A Multilevel Model of Safety Climate: Cross-Level Relationships Between Organization and Group-Level Climates. Journal of Applied Psychology, 90(4), 616-628. http://dx.doi.org/10.1037/0021-9010.90.4.616 